\title{
Improving the Moral Education System in Higher Vocational Colleges with the Concept of Practical Education
}

\author{
Meizhen Huang
}

Jiangxi College of Applied Technology, Ganzhou, Jiangxi, 341000 3107000933@qq.com

\begin{abstract}
To practice the idea of educating people as a guide to reform and improve the moral education system in higher vocational colleges. can play a very effective role. The importance of moral education in higher vocational colleges is obvious to all, students begin to accept moral education from primary school, and moral education has brought great help to the shaping of students' personality and the growth of their hearts. Taking the new era as the background, moral education must also play its greater value. And adapt to the changes of the new era, enhance its effectiveness, so moral education must be improved. And the practice of educating people can develop the core value of moral education to a greater extent, and make students be positively influenced and guided by moral education. This paper mainly focuses on the practice of education to improve the moral education system in higher vocational colleges.
\end{abstract}

Keywords: practice education; moral education

\section{用实践育人理念完善高职院校德育体系}

\author{
黄梅珍
}

\author{
江西应用技术职业学院, 贑州江西, 341000 \\ 3107000933@qq.com
}

\begin{abstract}
摘要
以实践育人理念作为导向，对高职院校的德育体系进行改革和完善。能够起到非常有效的作用。德育 在高职院校中的重要性是有目共睹的, 学生从小学就开始接受德育, 而德育给学生的人格的塑造以及 心灵的成长，都带来了非常大的帮助。以新时代为背景，德育也必须要发挥出其更大的价值。并适应 新时代的变化, 增强其有效性, 因此德育必须要进行完善。而实践育人理念, 能够更大程度的开发德 育的核心价值, 并使学生受到德育的积极影响和引导。本文就主要围绕用实践育人理念完善高职院校 德育体系进行研究和探讨。
\end{abstract}

关键词：实践育人；德育

\section{1. 实践育人的科学内涵}

在实践的基础上形成的育人理念, 也就是实践育人 理念, 实践育人理念是结合了理论知识和实践经验的, 因此实践运营理念能够对学生起到一定的引导作用, 引 导学生从实训活动中和生活中提取更多的有利于自身 发展的因素。而实际运营理念也提倡学校和教师应该给 学生更多的实践机会, 让学生参与更多的实践活动, 例 如志愿者服务, 又或是社会考察等, 通过这些活动能够 使学生得到思想政治教育, 也使学生的成长能够更加积
极和健康。而实践育人理念与传统育人理念的差异在于 传统育人理念主要是通过课堂教学来对学生起到教育 的作用, 但是说教式的教育方式容易使学生感到反感和 抗拒。而通过实践育人的方式, 就能够使学生在经历的 过程中得到成长, 受到教育, 而这样的过程是不会使学 生感到抗拒的。

首先通过实践, 学生能够更加了解社会, 并且学生 也能够更进一步的踏入社会, 在实践过程中, 学生所能 够学习到的不仅仅是生活技能, 学生也能够从中学习到 如何与人相处, 并且正确看待个人与社会与集体之间的 关系，因此实践育人是能够使学生对事物和人际关系的 理解更上一层楼的, 在高校育人环节中时间育人活动也 
是必不可少的, 不仅要从理论上对学生进行思想政治教 育, 还应该从实践中让学生受到思想政治教育, 而因为 实践育人理念更加贴合学生的日常生活, 因此往往不需 要教师对此进行说明, 学生也能够从这些经历中领悟到 一些道理，不过因为时间限制，所以目前的思想政治教 育的主要实施方式还是课堂教学方式, 实践教学方式只 是作为辅助的作用存在。而实践教学方式也是根据学生 的成长规律以及成长轨迹引导学生对自己进行自我管 理和自我约束的方式。实践育人理念也与传统育人理念 的差别在于传统育人理念对学生的行为和思想进行约 束和管教, 但是实践育人理念是引导学生对自己进行约 束。那么其本质差异就在于从被动到主动, 因此实践育 人理念的有效性要强于传统育人理念, 最后, 在实践育 人理念中也十分强调知行合一。学生要真正的将实践育 人过程中所学习到的东西运用到生活中, 融入到自己的 思想和行为里, 而提升思想政治教育的有效性, 也是为 了提升学生的思想高度。

而以实践育人作为德育体系的执行理念, 在开展德 育时贯彻实践育人理念, 就能够在一定程度上使德育的 有效性得到提升, 而同时, 因为实践育人能够在很大程 度上调动学生的学习兴趣, 因此学生能够更加投入到实 践育人活动中, 而实践育人理念所强调的就是实践育人 活动, 只有在实践育人活动中才能够突显出实践育人理 念的价值, 而也只有在实践育人活动中才能够发挥出德 育的实践职能。

从当前看来, 实践育人理念已经给予了德育的开展 一定的启发, 只是实践育人理念与德育还没能够得到完 全的融合, 还有一部分德育教师仍然只是将实践育人理 念当做一种理论, 而并非是具有一定的实践性的指导理 念。

如果德育教师能够正视实践育人理念, 并且借由实 践育人理念完善德育体系, 那么就能够在一定程度上提 升德育的有效性, 也能够使学生更加沉浸式的进入到德 育教学中, 学习更多德育知识, 提升自己的思想高度。 而且实践育人理念在德育中的价值的体现绝不仅止于 此, 对于学生而言, 实践育人活动能够在一定程度上帮 助学生拓宽视野, 使学生更加了解世界和社会, 也能够 使学生能够更加全面的去看待身边的事物。因此实践育 人活动, 也可以成为给予学成成长经验的过程。对成长 经验的积蓄, 不仅能够帮助学生建立更加正确的价值观 念, 具备更加健全的人格, 也能够使学生在日后步入社 会之后, 能够跟社会建立更加和谐的连接关系。因为实 践育人活动也能够在一定程度上帮助学生提升人际交 往能力, 而对于学生而言, 实践育人活动不仅仅是一种 德育开展的形式, 也是一种有趣的教学活动的形式, 因 此在这种有趣的教学活动中, 学生能够得到更多的生活 的成就感, 也能够从中领悟到很多道理, 而这些道理是 教师通过口头教育而难以传递到学生心中的, 因为学生 容易将教师所传授的道理看作是说教, 而如果是学生自 己去感悟和发现, 体验且总结得出的道理, 学生自然就 会遵守, 并且会据此来调整自己的行为方式和思想态 度。且因为在新时代背景下学生的个性越来越难以掌 握, 如果教师不利用实践活动的方式让学生释放自己的
天性, 并且在维护学生的个性的前提下, 让学生接触更 多的事物, 那么学生就很难得到思想上的改变。尤其是 当前学生大部分思想都十分独立自主, 很有自己的想 法, 更加难以被人动摇。而一些错误的思想观念, 如果 教师不予以注意并及时纠正, 那么就很有可能会在日后 对学生起到不良的引导。

\section{表 1 实践育人的科学内涵}

\begin{tabular}{|c|c|c|}
\hline $\begin{array}{c}\text { 在实践的基础 } \\
\text { 上形成的育人 } \\
\text { 理念, 也就是实 } \\
\text { 践育人理念, 实 } \\
\text { 践育人理念是 } \\
\text { 结合了理论知 } \\
\text { 识和实践经验 } \\
\text { 的, 因此实践运 } \\
\text { 营理念能够对 } \\
\text { 学生起到一定 } \\
\text { 的引导作用, 引 } \\
\text { 导学生从实训 } \\
\text { 活动中和生活 } \\
\text { 中提取更多的 } \\
\text { 有利于自身发 } \\
\text { 展的因素。而实 } \\
\text { 际运营理念也 } \\
\text { 提倡学校和教 } \\
\text { 师应该给学生 } \\
\text { 更多的实践机 } \\
\text { 会, 让学生参与 } \\
\text { 更多的实践活 } \\
\text { 动, 例如志愿者 } \\
\text { 服务, 又或是社 } \\
\text { 会考察等, 通过 } \\
\text { 这些活动能够 } \\
\text { 使学生得到思 } \\
\text { 想政治教育, 也 } \\
\text { 使学生的成长 } \\
\text { 能够更加积极 } \\
\text { 和健康。 }\end{array}$ & $\begin{array}{l}\text { 通过实践, 学生 } \\
\text { 能够更加了解社 } \\
\text { 会, 并且学生也 } \\
\text { 能够更进一步的 } \\
\text { 踏入社会, 在实 } \\
\text { 践过程中, 学生 } \\
\text { 所能够学习到的 } \\
\text { 不仅仅是生活技 } \\
\text { 能, 学生也能够 } \\
\text { 从中学习到如何 } \\
\text { 与人相处, 并且 } \\
\text { 正确看待个人与 } \\
\text { 社会与集体之间 } \\
\text { 的关系, 因此实 } \\
\text { 践育人是能够使 } \\
\text { 学生对事物和人 } \\
\text { 际关系的理解更 } \\
\text { 上一层楼的, 在 } \\
\text { 高校育人环节中 } \\
\text { 时间育人活动也 } \\
\text { 是必不可少的, } \\
\text { 不仅要从理论上 } \\
\text { 对学生进行思想 } \\
\text { 政治教育, 还应 } \\
\text { 该从实践中让学 } \\
\text { 生受到思想政治 } \\
\text { 教育, 而因为实 } \\
\text { 践育人理念更加 } \\
\text { 贴合学生的日常 } \\
\text { 生活。 }\end{array}$ & $\begin{array}{c}\text { 在实践育人 } \\
\text { 理念中也十 } \\
\text { 分强调知行 } \\
\text { 合一。学生要 } \\
\text { 真正的将实 } \\
\text { 践育人过程 } \\
\text { 中所学习到 } \\
\text { 的东西运用 } \\
\text { 到生活中, 融 } \\
\text { 入到自己的 } \\
\text { 思想和行为 } \\
\text { 里, 而提升思 } \\
\text { 想政治教育 } \\
\text { 的有效性, 也 } \\
\text { 是为了提升 }\end{array}$ \\
\hline
\end{tabular}

\section{2. 形成实践育人格局}

一直以来, 高职院校都非常关注德育体系的发展和 完善, 并多次对德育体系完善的路径进行探索和创新, 从而逐渐构建出了一套相对完整的德育体系, 因此高职 院校当前的德育体系中, 体现的不仅是德育理论知识, 也是德育的实践知识, 因此德育体系不仅倡导通过课堂 教学的方式对学生进行思想道德教育, 也倡导通过实践 教学的方式让学生从中得到更多的收获。 


\section{1 教育型实践}

学校也应该不定期的开设思想道德教育实践课程, 给予学生更多的实践学习的机会, 让学生能够在亲身体 验中, 得到思想上的突破, 同时, 在思想道德教育实践 活动中, 学生不仅能够更加深入而全面的掌握一定的思 想道德教育理论知识, 还能够增强自己对世界, 对社会, 对各式各样事物的感悟, 能够使学生的责任感得到提 升。而同时在思想道德教育实践活动中, 学校也应该加 强对学生的爱国主义教育, 带领学生去往烈士陵园等地 点, 让学生能够亲身感受爱国主义精神, 并继而受到爱 国主义精神的熏陶和影响, 渐渐树立起爱国主义精神。

如果思想道德教育课程设置中仅仅只有理论课程 的设置, 那么思想道德教育课程是十分单一且枯燥的, 而且只是单纯的理论课程, 并不能够深入的帮助学生掌 握思想道德教育课程的知识, 甚至于很容易让学生产生 对思想道德教育的反感和抗拒。只有通过实践才能够让 学生加强学习思想道德教育知识, 让学生的思想得到质 的改变。而且在思想道德教育理论课程中, 教师能够传 授给学生的只有一些理论层面的知识, 而这些理论知识 如何应用到现实中, 在现实中又将起到何种作用, 何种 影响, 学生是无从得知的, 因此对于这些理论知识的看 法也过于肤浅。但如果教师能够积极开展思想道德教育 实践课程, 并且带领学生进入到与思想道德教育有关的 实践操作中, 让学生亲身感受, 那么学生所得到的感悟 自然也就更加真诚, 而学生的记忆也会更加持久。通过 课堂上的学习, 学生的记忆往往只能够维持一小段时 间, 甚至于在考试的时候学生的记忆都会荡然无存, 这 主要是因为学生并没有完全的掌握这些理论知识, 而且 没有实践的辅助, 学生对这些理论知识的理解也仅限于 表面, 而想要使学生对这些理论知识的掌握更加长久, 也为了使学生的思想高度能够得到真正的提升, 那么就 必须要利用实践活动, 在实践活动中体现出实践育人的 理念, 利用实践提升学生的学习有效性。

表 2 建立实践育人保障体系

\begin{tabular}{|c|c|c|}
$\begin{array}{c}\text { 要有坚强的组 } \\
\text { 织保障 }\end{array}$ & $\begin{array}{c}\text { 重视教师和管理 } \\
\text { 人员的主体保障 } \\
\text { 作用 }\end{array}$ & $\begin{array}{c}\text { 完善实践育人 } \\
\text { 的工作机制 }\end{array}$ \\
\hline
\end{tabular}

\begin{tabular}{|c|c|c|}
\hline & 在以实践育人理 & \\
对大学生的思 & 念为引导的德育 & \\
想状况和学习 & 体系中, 主要的 & 将实践活动与 \\
学习状况进行 & 德育实施者是教 & 理论知识教学 \\
更加深入和全 & 师和管理人员, & 结合在一起, 才 \\
面的掌握和分 & 但是学生才是实 & 能够成就实践 \\
析, 并根据学 & 践育人的主体, & 育人理念, 而想 \\
生的基本情况 & 才是实践育人的 & 要发挥出实践 \\
来制定相应的 & 中心, 提升学生 & 育人理念的积 \\
德育计划, 以 & 的责任心, 培养 & 极作用, 就必须 \\
实践育人理念 & 学生爱国主义精 & 要完善实践育 \\
作为引导, 将 & 神, 就是实施实 & 人的工作机制。 \\
实践与课堂教 & 践育人理念的目 & 使学生能够从 \\
学结合在一 & 的, 而高校也应 & 实践活动中得 \\
起。 & 该提升教师和管 & 到积极影响。 \\
& 理人员对实践育 & \\
人的了解。 & \\
& & \\
\hline
\end{tabular}

\section{2 服务型实践}

公益活动的开展也属于思想道德教育实践活动的 一种, 带领学生参与到公益活动中, 能够培养学生的爱 心、同情心, 也能够使学生实现自己的社会价值和个人 价值, 让学生感受到为社会做贡献的快乐, 也能让学生 了解到更多的事物, 而公益活动有很多种, 无论是带领 学生去往孤儿院或是敬老院送温暖, 又或是带领学生下 乡种树等都属于公益活动。这些公益活动都是有利于社 会, 也有利于他人的, 因此学生也能够从中得到爱心上 的极大满足。

\section{3 文化实践型}

学校可以积极组织各式各样的文化节, 通过文化 节, 学生可以展现出自己的才能和自己的特长, 也能够 了解到各种不同的文化活动, 并在文化活动中得到动手 能力的提升, 而同时, 这些文化活动也丰富了学生的课 外生活, 还能够将学生的专业知识与实践结合在一起, 提升了学生的实践能力。因此, 通过开展文化活动, 能 够使学生得到全面的培养和锻炼。

\section{3. 结语}

实践育人理念在高校德育体系建设和完善的过程 中是存在其积极作用的, 而以实践育人理念作为引导, 完善高校德育体系, 就必须要加强对学生的实践教学, 为学生提供更多的参与实践活动的机会, 让学生能够在 参与实践活动的过程中, 得到美好品德的培养和健全三 观的塑造。同时，实践育人理念的出现也打破了传统育 
人理念给高校德育体系带来的桎梏。并且能够使学生从 被动化为主动, 在潜移默化中慢慢的受到高尚情操的影 响, 仅仅是从口头教育的方面是无法改变学生的思想 的, 想要为学生创造一个健康积极的成长环境, 就必须 从实践做起, 让学生从实践中自然领悟, 而不是强迫学 生接受教师所灌输的理论知识。

\section{REFERENCES}

[1] Shao Guangxia. On the Return of Life in MoralEducation[J]. Journal of Theory, 2006, (8).

[2] Lu Jie. Marginalization and externalization ofknowledge-themodernsyndromeofmoraleducation[J]. Educational Research, 2005, (12).

[3] Yi Lianyun. Interpretation of the meaning of life in traditional morality -- On the construction of moral system of "life practice "[ J]. Journal of Education, 2005, (5).

[4] Niu Jincheng. Reconstruction of the concept of moral education curriculum [J]. Education Review, 2007, (1).

[5] Zhou Guping. school ecological education in the new curriculum reform vision [J]. Course Materials Teaching Law, 2006, (12).

[6] Li Xiaolu. The overall thinking of moral education curriculum reform in primary and secondary schools $[\mathrm{J}]$. Ideological and Political Teaching, 2006, (3).

[7] Challenges and Countermeasures in Ideological and Political Education of College Counselors under the New Situation [J].] Li Jinlin. Intelligence. 2017(20)

[8] To explore and analyze the inner implication of ideological and political education of college students in the new era [J].] Fu Chen. Intelligence. 2017(05)

[9] Research on the Mode of Ideological and Political Education for College Students in the New Period [J].] Zhou Yuanxing. University education. 2017(09)

[10] Reflections on Strengthening Ideological and Political Education in Grass-roots Employment of College Students [11]Ma Xinmin, Gao Jie, Zhu Jiajun. Beijing Education (Moral Education). 2017(09)

[12] Problems and Countermeasures in Ideological and Political Education of College Students in New Period [J].] Chen Gongxin. Intelligence. 2017(26)

[13] Study on the Function of Ideological and Political Education in Colleges and Universities in the New
Period [J].] Money honey. Journal of Jiamusi Vocational College. 2017(07)

[14] A Study on Promoting the Ideological and Political Education of College Students in the New Era Based on the Work of Party Building [J].] Shi Yue. Intelligence. 2017(27)

[15] On the Innovation of Ideological and Political Education Methods in Colleges and Universities in the New J]. [Nan Lingling, Li Yuanyuan. Goods and quality. 2011(SB) 